\title{
EDITORIAL
}

\section{A importância da criação de uma revista científica em saúde, pelo HU-UNIVASF, para a comunidade acadêmica do Vale do Submédio São Francisco}

Fiquei bastante honrada pelo o convite e é um prazer poder contribuir com o primeiro editorial da Revista de Ensino, Ciências e Inovação em Saúde (RECIS).

Disponibilizar meios para publicação cientifica é de grande importância e de valiosa contribuição acadêmica-cientifica e social. O acesso à informação é um direito assegurado pela lei $\mathrm{n}^{0} 12.527$, de 18 de novembro de 2011. Assim, proporcionar meios de divulgação de informações cientificas ajuda na inserção social, na adoção de políticas públicas e na redução da desigualdade social.

Um exemplo de grande importância da divulgação cientifica na atualidade tem sido os grandes problemas gerados pela COVID-19. Essa doença tem exigido da comunidade cientifica uma rápida resposta quanto aos procedimentos e soluções para minimizar a os prejuízos causados na humanidade.

A visão interdisciplinar das pesquisas cientificas, em especial a área de saúde, tem sido cada vez mais de interesse da comunidade acadêmica-cientifica e exigida pelas instituições. A divulgação de pesquisas de livre acesso proporciona um grande avanço na solução de problemas e no conhecimento científico.

As informações expostas acima cabem muito bem para a RECIS. A revista surge com o intuito de promover a divulgação cientifica de acesso livre na área de saúde, tendo como foco uma visão interdisciplinar. Esse objetivo torna a RECIS atrativa para divulgação das suas pesquisas cientificas, como também, pode proporcionar melhoria na saúde da população, uma vez que, envolve necessariamente a incorporação de pesquisas e intervenções com uma variedade de abordagens interdisciplinares em seus domínios científicos e profissionais, conduzida sempre pela observação, análise, compreensão e interpretação de fatos de saúde. A revista também pode contribuir na implementação e direcionar ações de saúde eficientes e positivas para a população, comunidades e pessoas, isso pelo fato de proporcionar a divulgação cientifica em várias áreas do conhecimento com foco em saúde.

Além da relevância temática, a RECIS ajudará a minimizar as fronteiras e contribuirá na divulgação cientifica dando oportunidade, em especial, a divulgação da ciência brasileira como também a ciência internacional. A publicação em periódicos revisados por pares proporciona a revista o reconhecimento nacional e internacional da qualidade do que é publicado.

Enfim, escrever e publicar são meios de eternizar o conhecimento científico e a RECIS passa a proporcionar esse grande feito para a ciência brasileira e internacional. Assim, desejamos que a RECIS possa publicar temas de grande importância e de interesse nacional e internacional na área de saúde.

Profa. Dra. Josiclêda Domiciano Galvíncio

Galvíncio JD /Revista de Ensino, Ciência e Inovação em Saúde v.1n.1(2020) p. 2 